\title{
Finite Element analysis of stress state in the cement of total hip prosthesis with elastomeric stress barrier
}

\author{
Fadela Allaoua, Habib Lebbal, Abderrahmane Belarbi \\ Department of Mechanical Engineering, University of Science and Technology, Oran, Algeria \\ bouchamadila@gmail.com, bttps:/ / orcid.org/0000-0002-1440-5768 \\ lebbalh@yahoo.com, bttps://orcid.org/0000-0002-3514-857X \\ belarbi_abd@yahoo.fr, bttps://orcid.org/0000-0002-0245-241X
}

\begin{abstract}
In the total hip prosthesis, according to different positions of the patient, there are a variety of loads acting on femoral head which generate stress concentration in the cement called polymethylmethacrylat (PMMA) and consequently in interfaces stem/cement/bone. This load transfer can provoke loosening of the implant from the femoral bone. This paper focused on optimal stress distribution in the total hip prosthesis and devoted to the development of a redesigned prosthesis type in order to minimize stress concentration in the cement. This study investigated the effect of elastomeric stress barrier incorporated between the stem and femoral head using 3Dfinite element analysis. The proposed model provided an acceptable solution for load transfer reduction to the cement. This investigation enabled an increase of the service life of total hip prosthesis avoiding the loosening.
\end{abstract}

KEYwORDS. Hip prosthesis; Cement; Stress concentration; Stress barrier; Finite element method (FEM).

\section{OPEn 0 ACCESS}

Citation: Allaoua, F., Lebbal, H., Belarbi, A., Finite Element analysis of stress state in the cement of total hip prosthesis with elastomeric stress barrier., Frattura ed Integrità Strutturale, 57 (2021) 281-290.

Received: 16.05 .2021

Accepted: 07.06.2021 Published: 01.07.2021

Copyright: (C) 2021 This is an open access article under the terms of the CC-BY 4.0, which permits unrestricted use, distribution, and reproduction in any medium, provided the original author and source are credited.

\section{INTRODUCTION}

M any hip prostheses and fixation techniques have been introduced in orthopedics in recent years. Recently, the cemented total hip replacement based on Charnley low friction arthroplasty has proven outstandingly successful. The causes for long-term failure are characterized by the stem fracture, inadequate cementing or bad placement, but the introduction of high strength metal alloys and improved cemented techniques can increase their service lifetime. The stress patterns in the bone-prosthesis structure depend of the magnitudes and the orientations of the loads, the geometries of the structure, the mechanical properties of the materials and the physical conditions at material connections. During the polymethylmethacrylat (PMMA) polymerization process, exothermic chemical reaction leads to a crack formation when its propagation depends to practiced exercise activity by the patients as described by Charef and Serier [1] in one hand and in another hand stress analysis on stem is analyzed as performed by Colić et al. [2]. 
Mahmoud et al. [3] analyzed revision of the well-fixed broken stem of cemented hemiarthroplasty using anterolateral proximal femoral window. Also, the polished stems were predicted to induce a lower failure probability of cement mantle and higher integrity of the cement-stem interface when compared to the roughened stem and notable developments have included ceramic hip resurfacing and mini hip stems treated by [4]-[6] while topology and lattice in the optimized hip prosthesis design were performed to reduce stress shielding as shown by He et al. [7].

The Finite Element Method (FEM) is very suitable technique to interrelate these aspects quantitatively as shown by Huiskes and Chao [8] while Huiskes and Boeklagen [9] introduce a method of numerical shape optimization for prosthetic designs to minimize interface stresses. However, stress shielding of the femur is known to be a principal factor in aseptic loosening of hip replacements for that Joshi et al. [10] present a study which explore the hypothesis that through redesign, a total hip prosthesis can be developed to substantially reduce stress shielding and fracture behavior has been investigated of different alloy materials used in total hip prosthesis replacement implants by Sedmak et al. [11] and Gross and Abel [12] consider the use of a hollow stemmed hip implant for reducing the effects of stress shielding, while maintaining acceptably low levels of stress in the cement using finite element modeling. Also, no relationship between residual stress and observed cracking of cement has yet been demonstrated. To investigate if any relationship exists, a physical model has been developed by Lennon and Prendergast [13] which allows direct observation of damage accumulation around cemented femoral components of total hip replacements. About the experimental part, a project is based on the clinical observation that higher subsidence (distal migration) correlates with early revision of hip prostheses to develop a pre-clinical testing platform for cemented femoral hip implants as measured by Maher and Prendergast [14]. The relationship between cement fatigue damage and implant surface finish in proximal femoral prostheses has been treated by Lennon et al. [15] and has shown that, despite generally higher stresses in cement mantles of polished stems, the micro-damage does not apparently accumulate at a faster rate for those stems. A numerical study with four different stem shapes of varying curvatures for hip prosthesis was conducted by Senalp et al. [16] to determine the fatigue endurance of cemented implant and to reduce sliding of the implant in the bonecement. The effect of the position and orientation of a crack in the cement mantle under various loads using the finite element method has been studied [17-19]. In this work, a three dimensional finite element method was employed to analyze both conventional and proposed prosthesis. In the second one, an elastomeric stress barrier is incorporated between the stem and the femoral head in order to reduce the force transfer to the cement developed by Mehdi et al. [20]. The two models were modeled using Solidworks CAD Sofware.

\section{MATERIALS AND METHODS}

7 he total hip prosthesis with the principal components is presented in Fig. 1 while Fig. 2 shows two geometrical prosthesis models which are studied here: conventional model and redesigned model with an incorporated elastomer between the stem and the femoral head.
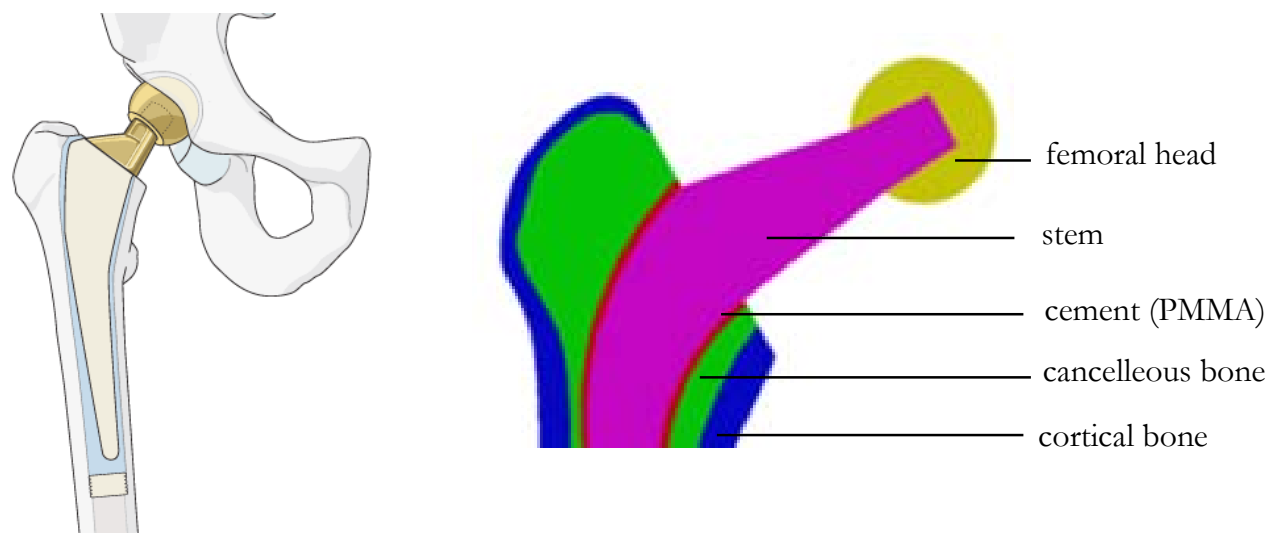

Figure 1: Geometric model of the total hip prosthesis 


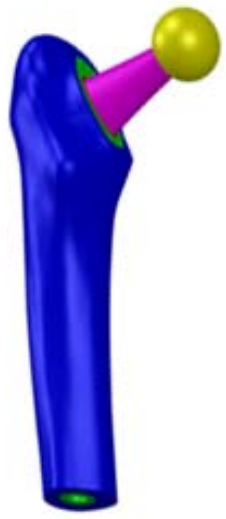

(a)

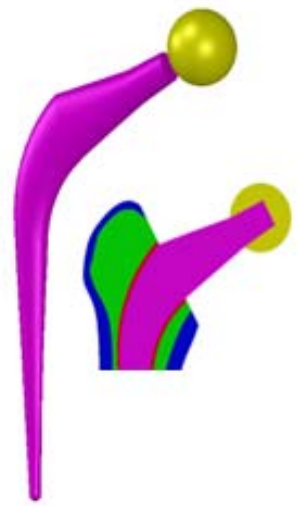

(b)

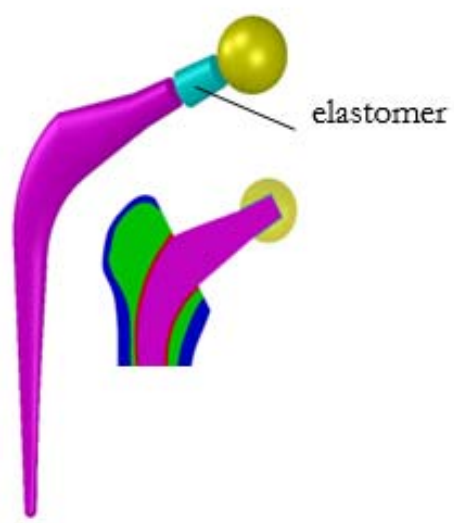

(c)

Figure 2: (a) Full model, (b) Detailed conventional model, (c) Detailed proposed model.

In reality, the femoral bone is an anisotropic material while the elastomer exhibits hyper-elastic behavior. For simplifying reasons, the mechanical behavior of all components was considered isotropic and linear elastic. Tab. 1 provides their mechanical elastic properties. For the proposed model, an elastomeric material of $0.5 \mathrm{~mm}$ thickness was added between the femoral head and the stem. The both models were meshed with quadratic tetrahedral elements C3D10 chosen due to the model shape complexity, Fig. 3a. The element size and type remain the same for the both models to avoid any influence of the mesh on the results.

\begin{tabular}{ccc}
\hline & Young Modulus $(\mathrm{MPa})$ & Poisson ratio \\
Cortical bone & 17000 & 0,3 \\
Cancelleous bone & 130 & 0,2 \\
PMMA & 2300 & 0,3 \\
Stem & 110000 & 0,3 \\
Femoral head & 110000 & 0,3 \\
Elastomer & 6 & 0,49 \\
\hline
\end{tabular}

Table 1: Mechanical properties of the hip prosthesis components.

Three types of loading configurations were addressed: Load 1, Load 2 and Load 3, depending on the high risk in the motion situations, are shown in Tab. 2. The forces in the 3 directions as well as their resultant are given in percentage according to the weight of the body of the patient which is equal to $750 \mathrm{~N}$.

\begin{tabular}{|c|c|c|c|c|c|}
\hline \multirow{3}{*}{ Load } & \multirow{3}{*}{ Movement } & \multicolumn{3}{|c|}{$\%$ Force weight } & Load \\
\hline & & \multicolumn{3}{|c|}{ Force components } & \multirow{2}{*}{$\frac{\text { Resulting force }}{\text { F }}$} \\
\hline & & $\mathrm{Fx}$ & Fy & $\mathrm{Fz}$ & \\
\hline Load 1 & Walk quickly $(5.3 \mathrm{Km} / \mathrm{h}$ or $1.47 \mathrm{~m} / \mathrm{s})$ & -52 & 33 & 243 & 251 \\
\hline Load 2 & Go down stairs (walking height : $17 \mathrm{~cm}$ ) & -60 & 39 & 253 & 261 \\
\hline Load 3 & Monopodal position & -32 & 17 & 230 & 232 \\
\hline
\end{tabular}

Table 2: Three loading situations with corresponding acting forces [13]. 


\section{BOUNDARY CONDITIONS}

A

$\mathrm{s}$ shown in Fig. 3b, the bottom of the femoral bone (cancelleous and cortical) is considered embedded: $\mathrm{Ux}=\mathrm{Uy}=\mathrm{Uz}_{\mathrm{z}}=\mathrm{URx}=\mathrm{URy}=\mathrm{URz}_{\mathrm{z}}=0$, while that of the cement is blocked only along the axis (zz): $\mathrm{Uz}_{\mathrm{z}}=0$. All interfaces are assumed fully bonded to ensure prosthesis stability.

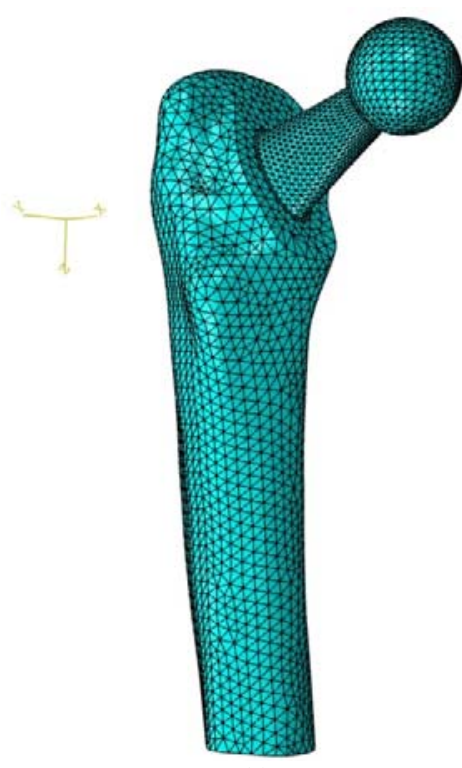

(a)

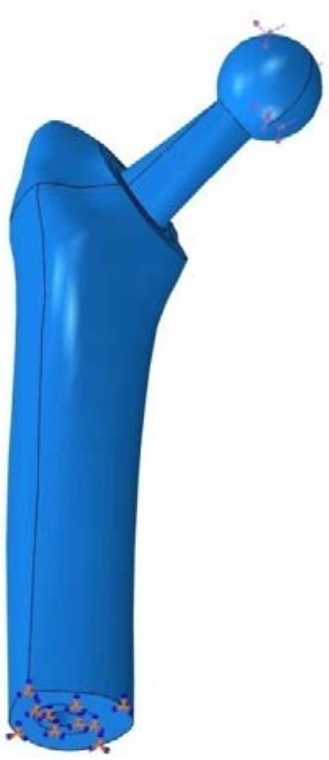

(b)

Figure 3: (a) Typical mesh, (b) Loading and boundary conditions.

\section{LOADING CONDITIONS}

he loading is introduced for each situation according to the 3 directions with the values listed in Tab. 2. Acting forces are defined as 3 components applied on the femoral head: Fx, Fy and Fz, Fig. 3b.

\section{ANALYSIS AND RESULTS}

$\mathrm{N}$

umerical analysis of the two models under identical loading and boundary conditions was carried out using Abaqus code based on finite element method (FEM) [22]. In order to compare stress levels, choice was on the cement body (PMMA), principal connexion between stem and bone ensures the stability of the prosthesis.

Fig. 4 presents the equivalent von Mises stress distribution in the cement (PMMA) in conventional and proposed models. It was observed that the high levels of stress values located in the stem/cement interface zone in the conventional model for the 3 situations are reduced in the proposed up to $35 \%$. This is due to the presence of the elastomeric material which plays a stress barrier role while forces are transferring into the interface.

Stress distribution in the cement body (PMMA) led to trajectories choice: external interface bone/cement AB-CD and internal interface stem/cement EFG as indicated in Fig. 5.

Fig. 6 shows the stress plot on the AB path for the three load cases. It is clear that point $\mathrm{A}$ is subjected to the highest levels of stress values for both models. Nevertheless, it is observed that in point A stress level increases in the proposed prosthesis case compared to the conventional one. The difference of this increase for the largest values varies for the three load cases $13.2 \%(9.8 \mathrm{MPa}$ to $11.1 \mathrm{MPa}) 14.1 \%(9.9 \mathrm{MPa}$ to $11.3 \mathrm{MPa}$ ) and 26.7\% (10.1 $\mathrm{MPa}$ to $12.8 \mathrm{MPa})$ respectively. 


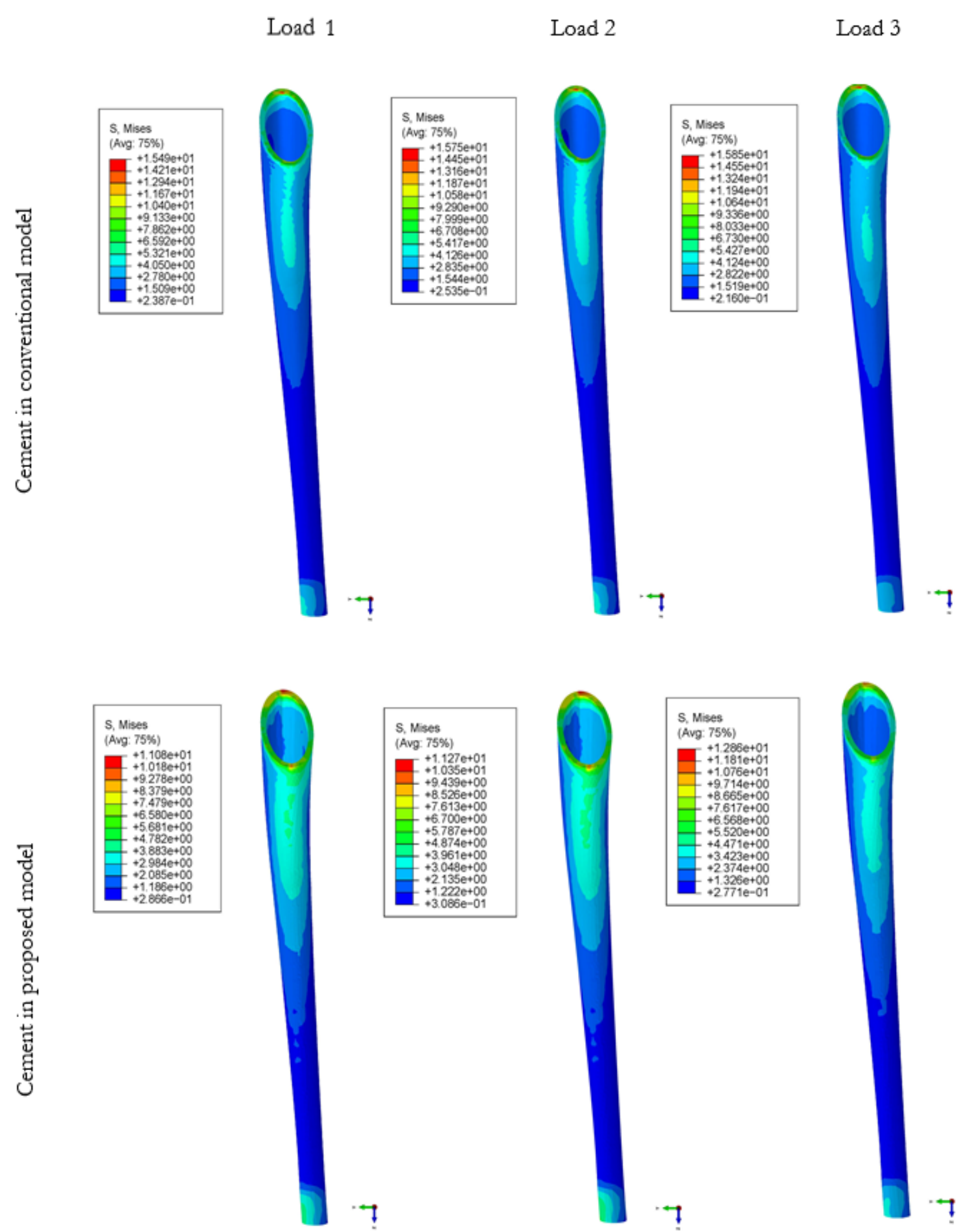

Figure 4: von Mises stress in the cement of both conventional and proposed models 


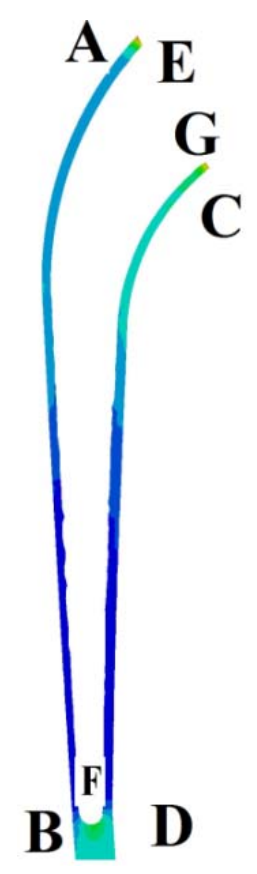

Figure 5: Stress path in the cement.
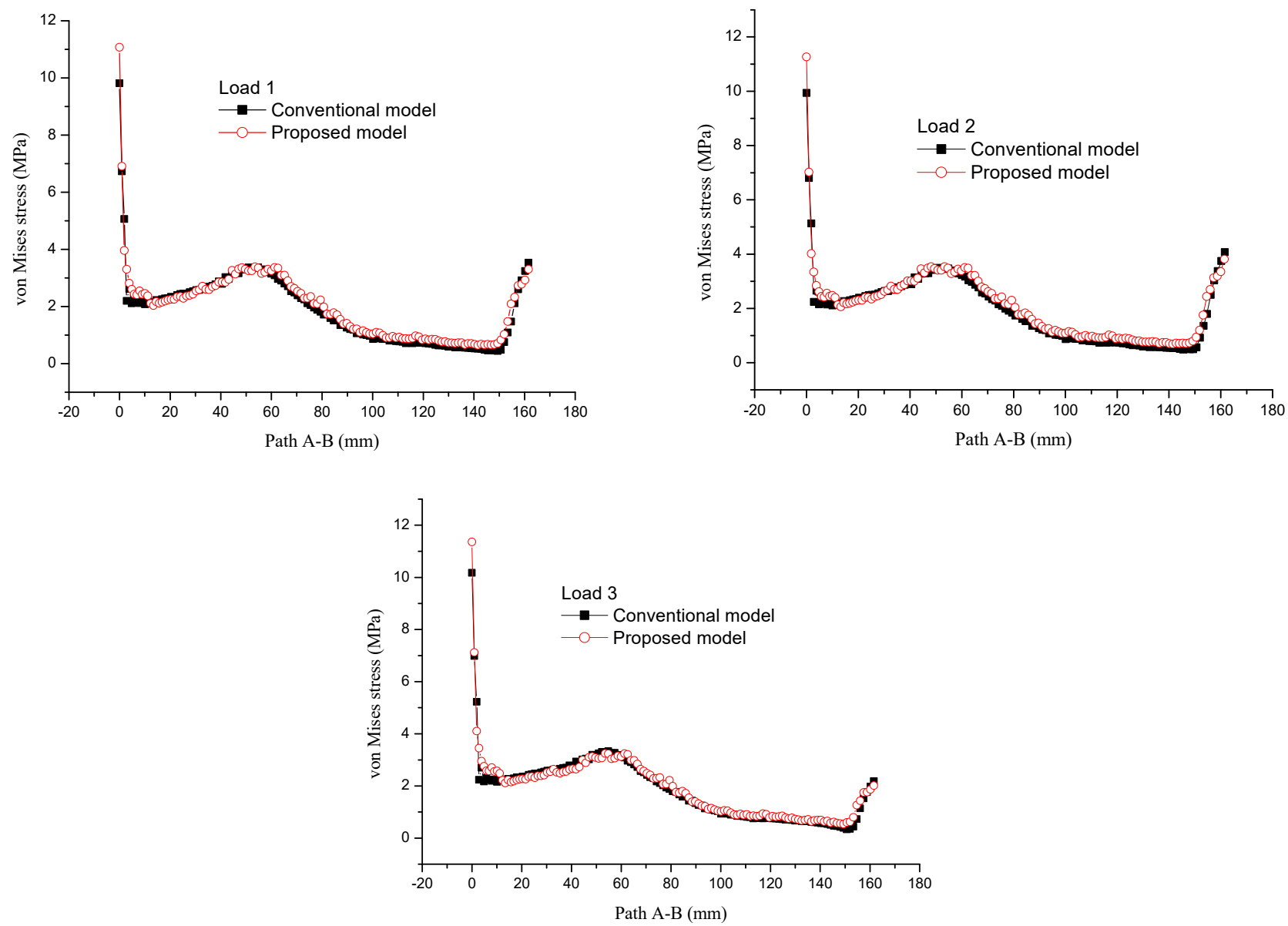

Figure 6: von Mises stress distribution along the cement path A-B for the three loading cases in the two models. 
In Fig. 7 stresses are shown on the $\mathrm{CD}$ trajectory, indicating the concentrated stress in point $\mathrm{C}$ with a lower level than point A for the two models. In the proposed model, the stresses also increase with a percentage varying from $42.8 \%(6.3$ $\mathrm{MPa}$ to $9.0 \mathrm{MPa}$ ), and $40.9 \%(6.6 \mathrm{MPa}$ to $9.3 \mathrm{MPa})$ to $45.9 \%(6.1 \mathrm{MPa}$ to $8.9 \mathrm{MPa})$.
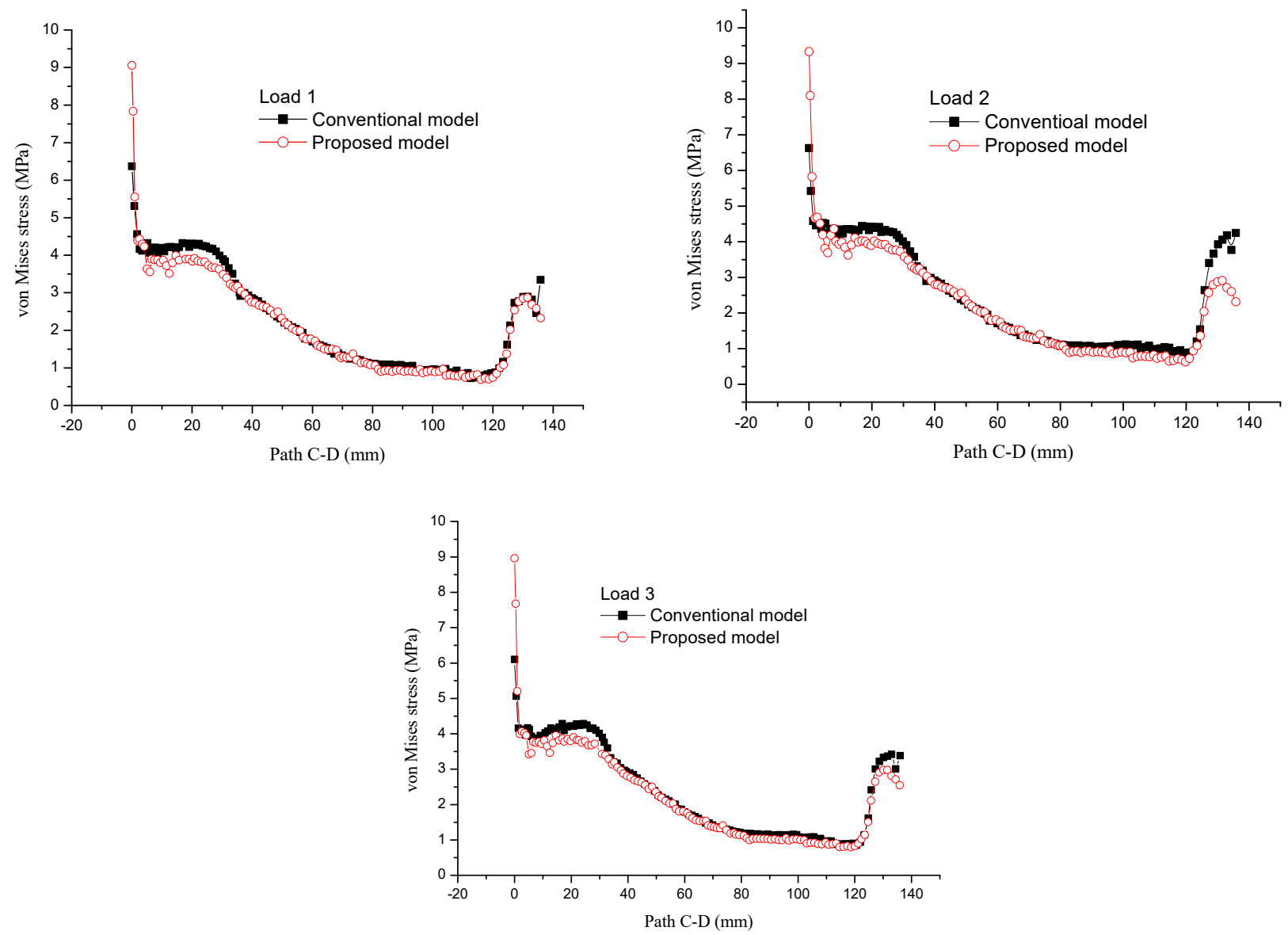

Figure 7: von Mises stress distribution along the cement path C-D for the three loading cases in the two models.

The stress path in the EFG interface is shown in Fig. 8 for the three different loads. In the conventional model it is noted that in point E, stresses are greater compared to those observed throughout the cement body. Contrary, in the proposed prosthesis the most concentrated zone observed a decrease in stress of $42.5 \%$ (15.5 MPa to 8.9 MPa), 42.0\% (15.7 MPa to $9.1 \mathrm{MPa}$ ) and $42.4 \%(15,8 \mathrm{MPa}$ at $9.1 \mathrm{MPa})$ under Load 1, Load 2 and Load 3 respectively. In particular, the case of the monopodal position seems to be the most dangerous.

In the proposed prosthesis, it is noted that the stress levels decreased in this interface and in particular in the point $\mathrm{E}$ which was the most stressed area in the whole body of the cement in the conventional prosthesis. The reduction in these highest stresses in the stem/cement interface, which is the most sensitive, is estimated approximately $42 \%$ depending of the load.

\section{Discussions}

$\mathrm{F}$ inite element analysis has shown, that the most stressed area of the cement in the conventional hip prosthesis are in the vicinity of point $\mathrm{E}$, in the internal cement/stem interface, being $15.5 \mathrm{MPa}, 15.7 \mathrm{MPa}$ and $15.8 \mathrm{MPa}$ with the three load types respectively. This is due to the eccentric compression loads inducing a bending moment that tends to debond the stem from the cement. This interface stress level proves to be dangerous since it can initiate an interfacial 
crack propagating down the prosthesis causing the loosening. Also, highest risk situations are those of walking down stairs and the monopodal position. However, the latter is not in common use while the descent of stairs can be frequent and cyclic if the patient lives in a building without elevator.

A solution of stress deconcentration is proposed to solve this problem. This involves introducing an elastomeric material between the femoral head and the stem which made it possible to reduce the stress level in point $\mathrm{E}$ by redistributing stress field in the cement. This elastomer, through its deformation, reduced a force transfer rate to the prosthesis components allowing more even distribution of stress in the entire cement body.
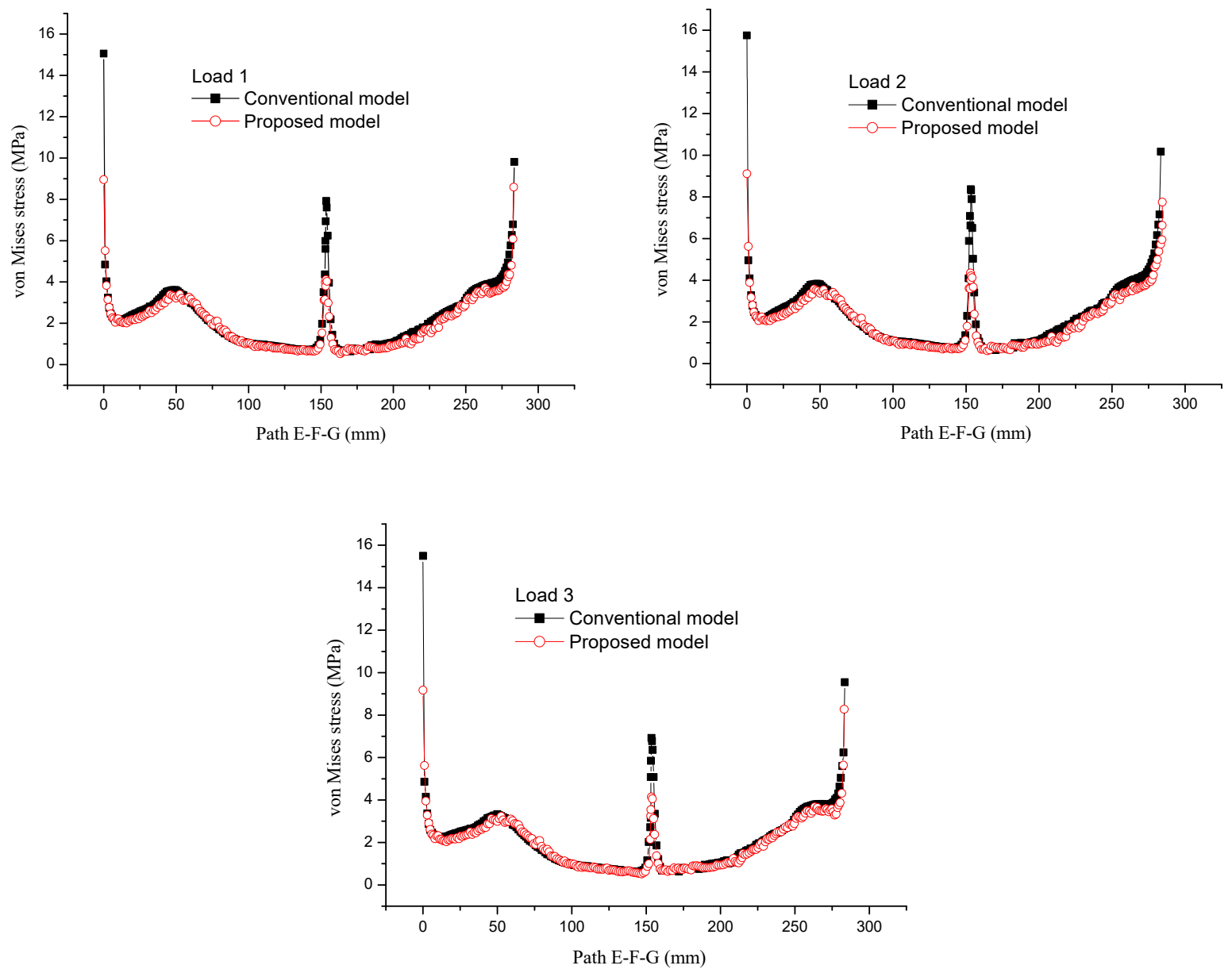

Figure 8: von Mises stress distribution along the cement path E-F-D for the three loading cases in the two models.

In the proposed prosthesis, for all the applied loads, the presence of the elastomer reduced the stress concentration at the point $\mathrm{E}$ in the conventional prosthesis by more even distribution of the stress field at the stem/cement interface. These redistributed stresses in the cement have increased at point $\mathrm{A}, 11.1 \mathrm{MPa}, 11.3 \mathrm{MPa}$ and $12.8 \mathrm{MPa}$, and are the highest compared to those of the other points. Consequently, the high stress levels in this concentrated interfacial zone stem/cement are reduced substantially while some other zones will increase their stress levels without reaching the peaks previously noted. However, the stress levels noted at points $E$ and $G$ which presented in important difference in the conventional prosthesis as $15.5 \mathrm{MPa} \sim 9.8 \mathrm{MPa}, 15.7 \mathrm{MPa} 10.1 \mathrm{MPa}$ and $15.8 \mathrm{MPa} \sim 9.5 \mathrm{MPa}$ were not significantly different in this redesigned prosthesis 8.9 MPa 8.6 MPa, 9.1 MPa 7.7 $\mathrm{MPa}$ and 9.1 $\mathrm{MPa} \sim 8.3 \mathrm{MPa}$. Anyhow, the numerical models used in the study are based on some important limitations, notably those related to the constitutive laws of bone materials and to the characterization of the elastomer. 


\section{CONCLUSIONS}

I $\mathrm{n}$ this finite element analysis of both conventional and elastomeric prosthesis, it was concluded that:

- The obtained stresses in cement/stem interface using the new proposed prosthesis with elastomeric material are generally lower than those found with the conventional model.

- Relative high stresses were observed at the cement/stem interface of the conventional model with the three load types.

- The use of soft and flexible elastomer positioned between the stem and the femoral head with low rigidity is able to reduce the load transfer to cement.

- The maximum stress concentration has moved from the cement/stem interface (in the conventional model) and reduced to the bone/cement interface (proposed model) because of the static equilibrium of forces in the new system.

- The stress levels reduction in the cement of the proposed prosthesis is estimated at $42 \%$.

In conclusion, the use of a shock absorbing elastomeric material appears to play a key role in the charge of transfer mechanism and the cement response. This stress absorber reduces the stress on the cement and thus increases its service life avoiding the loosening.

\section{ACKNOWLEDGMENTS}

7 he authors extend their appreciation to the Director of Scientific Research at LaBPS for funding the work through the Biomechanics Research Group.

\section{REFERENCES}

[1] Charef, D., Serier, B. (2017). Prediction of Crack Propagation Direction in the Cemented Total Hip Prosthesis, Mechanics and Mechanical Engineering. 21(3), pp. 703-716.

[2] Colić, K., Sedmak, A., Grbovic A., Tatic U., Sedmak S., Djordjevic B. (2016). Finite element modeling of hip implant static loading, International conference on manufacturing engineering and materials, ICMEM 2016, Procedia Engineering, 149, pp. 257-262

[3] Mahmoud, M.M.M., Ibrahim, B., Amr, A. A., and Bayoumy, M.A. (2021). Anterolateral Bone Window for Revision Broken Cemented Stem of Unipolar Hemiarthroplasty, Adv. in Orthopedics, pp. 1-5.

[4] Hung, J.P., Bai, Y.W., Hung, C.Q. and Lee, T.E. (2019). Biomechanical Performance of the Cemented Hip Stem with Different Surface Finish, Appl. Sci., 9(19), pp. 1-16.

[5] Hoskins, W., van Bavel, D., Lorimer, M., de Steiger, R.N. (2018). Polished cemented femoral stems have a lower rate of revision than matt finished cemented stems in total hip arthroplasty: an analysis of 96,315 cemented femoral stems, J. Arthroplasty, 33(5), pp. 1472-1476.

[6] Marsh, M. and Newman, S. (2021). Trends and developments in hip and knee arthroplasty technology, Journal of Rehabilitation and AssistiveTechnologies Engineering, 8, pp. 1-9.

[7] He, Y., Durocher, D., Burkhalter, D., Gilbert, J. M. (2018). Solid-Lattice Hip Prosthesis Design: Applying Topology And Lattice Optimization To Reduce Stress Shielding From Hip Implants, Proceedings of Design of Medical Devices Conference, Minneapolis, MN, USA, pp. 1-5, April 9-12.

[8] Huiskes, R. and Chao, E.Y-S. (1983). A survey of finite element methods in orthopaedic biomechanics: the first decade, J. Biomechanics 16(6), pp. 385-409. DOI: 10.1016/0021-9290(83)90072-6.

[9] Huiskes, R. and Boeklagen, R. (1989). Mathematical shape optimization oh hip prosthesis design. J. Biomechanics 22(8-9), pp.796-804. DOI: 10.1016/0021-9290(89)90063-8.

[10] Joshi, M.G., Advani, S.G., Miller, F., Santare, M.H. (2000). Analysis of a femoral hip prosthesis designed to reduce stress shielding. J. Biomechanics 33(12), pp.1655-1662. DOI: 10.1016/s0021-9290(00)00110-x.

[11] Sedmak, A., Colić, K., Burzić, Z., Tadić, S. (2010). Structural integrity assessment of hip implant made of cobaltchromium multiphase alloy, Structural Integrity and Life, 10, pp.161-164

[12] Gross, S. and Abel, E.W. (2001). A finite element analysis of hollow stemmed hip prostheses as a means of reducing stress shielding of the femur. J. Biomechanics, 34(8), pp.995-1003. 
[13] Lennon, A.B. and Prendergast, P.J. (2001). Residual stress due to curing can initiate damage in porous bone cement: experimental and theoretical evidence. J. Biomechanics 35(3), pp.311-321. DOI: 10.1016/S0021-9290(01)00216-0.

[14] Maher, S.A. and Prendergast, P.J. (2002). Discriminating the loosening behaviour of cemented hip prostheses using measurements of migration and inducible displacement. J. Biomechanics 35(2), pp.257-265. DOI: 10.1016/S0021-9290(01)00181-6.

[15] Lennon, A.B., McCormack, B.A.O., Prendergast, P.J. (2003). The relationship between cement fatigue damage and implant surface finish in proximal femoral prostheses. Medical Engineering \& Physics 25(10), pp.833-841. DOI: 10.1016/S1350-4533(03)00120-6.

[16] Senalp, A. Z., Kayabasi, O., Kurtaran, H. (2007). Static, dynamic and fatigue behavior of newly designed stem shapes for hip prosthesis using finite element analysis. Materials and Design 28(5), pp.1577-1583. DOI: 10.1016/j.matdes.2006.02.015.

[17] Bachir Bouiadjra, B., Belarbi, A., Benbarek, S., Achour, T., Serier, B. (2007). FE analysis of the behaviour of microcracks in the cement mantle of reconstructed acetabulum in the total hip prosthesis. Computational Materials Science 40(4), pp.485-491. DOI: 10.1016/j.commatsci.2007.02.006.

[18] Ouinas, D., Flliti, A., Sahnoun, M., Benbarek, S., Taghezout, N. (2012). Fracture Behavior of the Cement Mantle of Reconstructed Acetabulum in the Presence of a Microcrack Emanating from a Microvoid. Int J. of Materials Engineering, 2(6), pp.90-104. DOI: 10.5923/j.ijme.20120206.04.

[19] Bounoua N., Belarbi, A., Belhouari M., Bachir Bouiadjra, B. (2014). Stress intensity factors for micro-crack emanating from micro-cavity in cement of reconstructed acetabulum. Mechanika, 20(6), pp.527-534.

DOI: $10.5755 /$ j01.mech.20.6.9157.

[20] Mehdi, G., Belarbi, A., Mansouri, B., Azari, Z. (2015). Numerical study of effect of elastomeric stress absorbers on stress reduction in bone-dental implant interface. J Appl Oral Sci., 23(1), pp.87-93. DOI: $10.1590 / 1678-775720140086$.

[21] Foucat, D. (2003). Effets de la présence d'un grillage métallique au sein du ciment de scellement des cupules des prothèses totales de hanche. Etude mécanique et thermique. Thèse de doctorat, université de Strasbourg. Laboratoire d'Ingénierie des Surfaces de Strasbourg (L.I.S.S. - EA 3435), I.N.S.A. de Strasbourg. http://scd-theses.ustrasbg.fr/821/01/ThèseFoucat.pdf.

[22] Abaqus/CAE Ver 6.9 (2007). User's Manual. Hibbitt, Karlsson \& Sorensen, Inc. 